\title{
Basic Numeracy Skills and Practice
}




\section{Basic Numeracy Skills and Practice}

J. Newbury, PhD

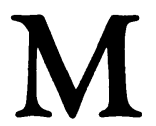


(C) J. Newbury 1981

All rights reserved. No part of this publication may be reproduced or transmitted, in any form or by any means, without permission.

First published 1981 by

THE MACMILLAN PRESS LTD

London and Basingstoke

Companies and representatives throughout

the world

ISBN 978-1-349-05560-9 ISBN 978-1-349-05558-6 (eBook)

DOI 10.1007/978-1-349-05558-6

Typeset in 10/12 Century by Illustrated Arts

The paperback edition of this book is sold subject to the condition that it shall not, by way of trade or otherwise, be lent, resold, hired out, or otherwise circulated without the publisher's prior consent in any form of binding or cover other than that in which it is published and without a similar condition including this condition being imposed on the subsequent purchaser. 


\section{Contents}

Preface vii

1 Introduction to Mathematics 1

2 Fractions 5

3 Negative Numbers $\quad 10$

4 Revision Exercises: Simple Equations and

5 Quadratic Expressions 23

6 Expanding Brackets 26

7 Restoring Brackets 28

8 Graphs and Co-ordinates 31

9 Equation of a Straight Line 39

10 Equation to Graph 43

11 Solving Simultaneous Equations Graphically 45

12 Solving Simultaneous Equations Algebraically 46

13 Revision: Equations: Graphs 51

14 Quadratic Equations $\quad 60$

15 Solving Quadratic Equations by Formulae 64

16 Linear Interpolation $\quad 67$

17 Indices $\quad 73$

18 Revision: Indices $\quad 79$

19 Logarithms $\quad 81$

20 Errors and Significant Figures $\quad 90$ 
vi Contents

21 Angles, Triangles and Trigonometrical Functions 92

22 General Revision $\quad 98$

Answers to Exercises $\quad 107$

Answers to Revision Chapters 4, 13 and $18 \quad 127$

Answers to General Revision Chapter 22 


\section{Preface}

This text presents the basic numeracy skills required in an introductory course in mathematics. The skills are presented through a series of logical steps that will establish confidence in attempting any of the questions. The text is suitable for children and teachers in primary schools, for pupils starting a course in CSE mathematics at the various modes, and for the adult returning to study after a number of years. It is suitable for self-help group teaching or for individuals working by themselves.

The text may be used as a primary teaching book or supplementary material to a main textbook. To facilitate ease of working, exercises are graded within each group from elementary to more complex since I believe proficiency in mathematics is directly related to practice.

The text commences with an introduction to the way problems may be attempted and progresses through fractions, numbers, transposition, equations, graphical methods and their applications, to indices, logarithms and finally an introduction to angles and trigonometrical ratios.

Each chapter presents the theory and principles which are then applied through worked examples. At the end of each section additional questions are presented. Revision exercises are found at intermediate parts of the book - the answers at the end of the book are amplified where necessary, especially in the case of graphical questions. The text has been presented such that the student may study progressively or use individual sections without loss of clarity.

The combination of presenting the principles and concepts of elementary numeracy through worked examples and 


\section{viii Preface}

additional graded questions will I trust give confidence to the reader. The questions, exercises and solutions are completely my responsibility.

I thank colleagues and students who have given advice whilst the manuscript has been in preparation. To John Watson and Peter Milford of Macmillan Press my special thanks throughout the preparation and editorial stages. 